\title{
EDUCAÇÃO INCLUSIVA: PELO DIREITO A PERTENCER
}

Jaira Couto Cruz

\begin{abstract}
RESUMO
O presente artigo elege como centro de seus debates as questões voltadas à educação inclusiva, evidencia as suas reflexões sob os aspectos legais e metodológicos que possibilitam a efetivação dessa modalidade de ensino e ainda discute os impactos que os alunos com deficiência trazem a escola. Para tanto, procura apontar por meio de uma investigação, como a educação tem promovido a inserção das pessoas com deficiência em seus espaços. Na concepção dos referenciais estudados, estão Mantoan (2006), Sassaki (1997), Mazzota (2005) entre outros estudiosos que se dedicam a discutir os meandros que orbitam a educação inclusiva tais como; relação coordenação pedagógica corpo docente, formação docente, legislações destinadas à educação inclusiva e sobretudo, o Atendimento Educacional Especializado - AEE. Os resultados desta obra desvelam o contexto contemporâneo da educação inclusiva e se atentam em sinalizar a possibilidade de uma efetiva mudança na realidade educacional.
\end{abstract}

Palavras-chaves: Inclusão. Desafío. Escola.

\section{INCLUSIVE EDUCATION: FOR THE RIGHT TO BELONG}

\begin{abstract}
The present article chooses as the center of its debates the issues of inclusive education, evidences its reflections under the legal and methodological aspects that make possible the effectiveness of this modality of education and also discusses the impacts that students with disabilities bring to school. To this end, it seeks to point out through an investigation, how education has promoted the insertion of people with disabilities in their spaces. Mantoan (2006), Sassaki (1997), Mazzota (2005) among other scholars are dedicated to discuss the intricacies of orbiting inclusive education such as; pedagogical coordination relationship - faculty, teacher training, legislations for inclusive education and, above all, Specialized Educational Assistance - ESA. The results of this work reveal the contemporary context of inclusive education and attempt to signal the possibility of an effective change in educational reality.
\end{abstract}

Keywords: Inclusion. Challenge. School

\section{EDUCACIÓN INCLUSIVA: POR EL DERECHO A PERTENECER}

\section{RESUMEN}

El presente artículo elige como centro de sus debates las cuestiones dirigidas a la educación inclusiva, evidencia sus reflexiones bajo los aspectos legales y metodológicos que posibilitan la efectividad de esa modalidad de enseñanza y aún discute los impactos que los alumnos con discapacidad traen la escuela.

Jaira Couto Cruz: Pedagoga, Psicopedagoga, Especialista em Educação Inclusiva, Mestranda em Ciências da Educação (77) 98857-6585 (whats) - jairacoutocruz@ hotmail.com 
Para ello, busca apuntar por medio de una investigación, como la educación ha promovido la inserción de las personas con discapacidad en sus espacios. En la concepción de los referenciales estudiados, están Mantoan (2006), Sassaki (1997), Mazzota (2005) entre otros estudiosos que se dedican a discutir los meandros que orbitan la educación inclusiva tales

como; - relación coordinación pedagógica - cuerpo docente, formación docente, legislaciones destinadas a la educación inclusiva y sobre todo, el Atención Educativa Especializada - AEE. Los resultados de esta obra desvelan el contexto contemporáneo de la educación inclusiva y se atentan en señalar la posibilidad de un cambio efectivo en la realidad educativa.

Palabras claves: Inclusión. Desafío. escuela

\section{INTRODUÇÃO}

A educação formal atual tem se deparado com diversas demandas pedagógicas/sociológicas no que diz respeito à educação especial na perspectiva da educação inclusiva. Não raro, nos deparamos com dificuldades que vão desde a parte metodológica, passando pela reordenação curricular, pela formação docente, entre outros elementos que compõe o arcabouço da escola.

Embora a LDB/9394/96 Lei de Diretrizes e Bases da Educação Nacional de dezembro de 1996, a LBI - Lei Brasileira de Inclusão e Diretrizes Estaduais e Nacionais se dediquem em seus escritos à garantia para que pessoas com algum tipo de deficiência, intelectual, sensorial ou física sejam incluídas nos espaços escolares, na prática, esta garantia não tem se constituído com a efetividade necessária.

Ocorre que a educação escolar que se apresenta está constituída sob a lógica que concebe o ideário do "perfeito e normal" e refuta as diferenças, elemento inerente ao ser humano. Isto acaba tornando a educação inclusiva um problema inexistente e, portanto, sem necessidade de debates e reflexões. Mazzota acredita que:

O movimento mundial pela educação inclusiva é uma política, cultura, social e pedagógica, desencadeada em defesa do direito de todos os alunos de estarem juntos, aprendendo e participando, sem nenhum tipo de discriminação (MAZZOTA, 2005, p. 9).

Este artigo é o resultado de observações e apreensões realizadas durante a construção da dissertação que escrevemos para obtenção de título de mestre e tem por objetivo trazer ao cento das discussões os meandros que permeiam a efetivação da educação especial.

Aqui nos atentaremos a evidenciar como a educação é algo orgânico, sistêmico e interdependente, como educar para as diferenças preconiza articulação entre os agentes da educação e, sobretudo, como pensar a inclusão na/da escola reverbera em uma sociedade afeta ao aprimoramento entre as relações. 


\section{ELEMENTOS QUE COMPÕEM A EDUCAÇÃO INCLUSIVA}

A Lei de Diretrizes e Bases da Educação (LDB) recentemente fez alterações com o objetivo de otimizar o ensino de forma que partindo delas, as instituições pudessem atender às crianças da comunidade independente de suas especificidades, sejam elas de ordem cognitiva, sensorial, física ou algum transtorno global do desenvolvimento. Tais modificações fizeram com que surgissem algumas confusões acerca das nomenclaturas.

A educação especial utiliza-se de instrumentos didáticos específicos para reabilitar a criança partindo de sua limitação, sejam elas físicas, cognitivas, sensórias ou transtorno global do desenvolvimento (TGD). A educação especial, não tem como prioridade integrar a criança a sociedade, uma vez que se aplicada fora da esfera da educação regular.

No entanto, a educação inclusiva é um sistema híbrido que atrela as duas esferas: educação regular e educação especial, ou seja, as crianças com algum tipo de deficiência são inseridas no contexto da escola regular. Nesse sentido, para que não haja prejuízos no rendimento escolar dessas crianças e que seu processo de reabilitação não sofra regressões são necessária reestruturação da escola tanto no âmbito físico, quanto na capacitação dos professores e dos demais profissionais da instituição para que saibam lidar com esses alunos com um perfil diferenciado. De acordo com Mantoan:

Inclusão é a nossa capacidade de entender e receber o outro e, assim, ter o privilégio de conviver e compartilhar com pessoas deferentes de nós. A educação inclusiva acolhe todas as pessoas, sem exceção. É para o estudante com deficiência, física, para os que têm comportamento mental, para os superdotados, e para toda criança que é discriminada por qualquer outro motivo. Costumo dizer que estar junto é se aglomerar no cinema, no ônibus e até na sala de aula com pessoas que não conhecemos. Já inclusão é estar com, é interagir com outro. (MANTOAN, 2005, p. 96).

É no contexto do que coloca a autora que evidenciamos a necessidade de um arcabouço escolar estruturado para atender de maneira efetiva estes estudantes. Destaca-se dentre outros aportes, o Atendimento Educacional Especializado - AEE

O AEE quando concebido corretamente representa nesta conjuntura, a articulação exitosa entre a coordenação pedagógica da escola, a formação docente, os espaços arquitetônicos, o ajuste do programa de currículo e acima de tudo, da prática docente que ao se dar de forma sensível, promove a educação de fato, inclusiva.

As atividades desenvolvidas no atendimento educacional especializado diferenciam-se daquelas realizadas na sala de aula comum, não sendo substitutivas a escolarização. Esse atendimento complementa e/ou suplementa a formação dos alunos com vistas a autonomia e independência na escola e fora dela (BRASIL, 2008, p.10). 
A Escola é um espaço onde perpassa a diversidade humana, ela apresenta-se como representação da sociedade. Se conseguimos incluir os diferentes na escola, estaremos projetando as ideias de respeito a diversidade humana de forma global.

\section{DELINEAMENTO METODOLÓGICO}

Este trabalho ocorreu utilizando uma pesquisa exploratória com análise de natureza qualitativa dos dados, adotando o método empirista, onde se buscou investigar por meio da utilização de questionário de natureza simples, aberto e da observação, como se tem construídos na atual conjuntura nas salas de aula do ensino fundamental, anos iniciais as metodologias que contemplem a aprendizagem dos alunos com Deficiência.

Segundo Malhotra (2006, p.156), a pesquisa com natureza qualitativa "é uma metodologia de pesquisa não-estruturada e exploratória baseada em pequenas amostras que proporcionam percepções e compreensão do contexto do problema”.

A investigação foi realizada com levantamento de dados em uma escola pública do município de Itapetinga-BA, de médio porte, com um contingente de 315 alunos, distribuídos em 06 (seis) salas de aulas que funcionam nos turnos matutino e vespertino com um número total de 12 turmas e estudantes na faixa etária compreendida entre 04 (quatro) e 15 (quinze) anos.

A escola ainda dispões de uma sala de Atendimento Educacional Especializado utilizada para atender alunos com dificuldade de aprendizagem e/ou deficiência intelectual que são atendidos por 02 (dois) profissionais. Que podem assim serem descritos: um tem formação no ensino Técnico de Magistério e graduação em Assistente Social. O outro profissional tem graduação em Pedagogia. O Atendimento Educacional Especializado é orientado por uma pedagoga, pós-graduada em psicopedagogia e especialista em Educação Inclusiva.

As observações, assim, como a aplicação dos questionários, foram acordadas com os envolvidos na pesquisa e ocorreram em momentos em que o grupo semanalmente faz reuniões (conselhos de classe, ou AC - Atividades Complementares). Os registros resultantes desta coleta de dados foram feitos ao final de cada observação, realizada no sentido de fidelizar as impressões coletadas.

Segundo Lüdke e André (1986, p. 26), "na medida em que o observador acompanha in loco as experiências diárias dos sujeitos, pode tentar apreender a sua visão de mundo, isto é, o significado que eles atribuem à realidade que os cerca às suas próprias ações”.

Em relação ao questionário que neste objeto foi semiestruturado, o mesmo "[...] favorece não só a descrição dos fenômenos sociais, mas também sua explicação e a compreensão de sua totalidade [...]" além de manter a presença consciente e atuante do pesquisador no processo de coleta de informações (TRIVIÑOS, 1987, p. 152). 
No que concerne à observação de perspectiva não-participante, a mesma foi utilizada para perceber os movimentos relacionais dentro do ambiente escolar no que tange educadores e coordenação pedagógica. “A observação não participante também pode ser conhecida como simples. O pesquisador permanece alheio à comunidade ou processo ao qual está pesquisando, tendo um papel de espectador do objeto observado (GIL, p. 37 2007)".

Para a concretização da pesquisa, inicialmente existiram contatos documentados com a gestão da escola, onde constou o nome da instituição a qual o pesquisador está vinculado, o objetivo da pesquisa em questão, bem como, todas as suas informações inerentes, o perfil dos potenciais envolvidos na investigação e ainda, o termo de aceite, indicando a sua permissão.

Uma vez dada uma resposta positiva à realização da pesquisa, o investigador com a anuência/participação da gestão fará a escolha do espaço físico no qual será realizada a observação e o questionário. O questionário semiestruturado foi aplicado, com o desejo de possibilitar o desenvolvimento da coleta de dados em horário de Atividade Complementar (AC), momento de planejamento das atividades pedagógicas, e reflexão das atividades aplicadas anteriormente Momento de encontro entre professores e coordenação pedagógica com desejo de promover o diálogo sobre temática.

A sala de realização do AC, é um espaço habitual desta e de outras atividades caracteristicamente coletivas onde se discutem questões pertinentes à escola. Esta condição oportunizou ao pesquisador a realização de observações de forma neutra a dinâmica existente, bem como a disponibilidade dos professores para participar da pesquisa. As perguntas são fechada e apresentam algumas prováveis respostas, com vários pontos de vista sobre o mesmo.

Finalizada a pesquisa os questionários foram recolhidos e os dados analisados, o que possibilitou a formulação e o resultado da pesquisa.

\section{RESULTADOS E DISCUSSÕES}

Nesse capítulo traremos uma discussão acerca de como está posta a inclusão de alunos com deficiência intelectual, uma escola de Itapetinga que se propõe a ofertar o Atendimento Educacional Especializado, visto que a mesma faz parte do Projeto Piloto de Educação Inclusiva implantado pela Secretaria de educação e Cultura no ano de 2015. O referido projeto visava atender crianças com deficiência de modo geral, formando professores multiplicadores, partindo da experiência e formação que deveria ser ofertado naquela escola. A escola investigada aqui será chamada de Escola de Inclusão e os professores bem como corpo docente serão mantidos no anonimato para que possamos preservar suas identidades.

O escopo desta investigação centrou-se em perceber como se tem dado o trabalho da coordenação pedagógica e corpo docente com a inclusão de alunos com deficiência intelectual. Para tanto, foi utilizado como espaço amostral e as considerações de $10(\mathrm{dez})$ professores de uma escola 
municipal da cidade de Itapetinga-BA. Nesse sentido reentra-se que a escola investigada, faz parte do Projeto Piloto de Educação Inclusiva, implantado pela Secretaria de Educação e Cultura do município.

\section{Questão - 01}

Em seu local de trabalho a Coordenação Pedagógica e corpo docente desenvolvem metodologias voltadas para a aprendizagem de alunos com Deficiência Intelectual? Explique sua resposta.

Essa pergunta provocou uma inquietação no grupo de professores, uma vez que o questionário, embora tenha sido respondido individualmente e espontaneamente, proporcionou um diálogo entre os presentes, pois o momento escolhido para tal atividade é habitual de conselho de classe onde encontram-se corpo docente e coordenação pedagógica. Orsolon (2003, p.21) evidencia a importância da observação das práticas nas reuniões como centro do trabalho grupal:

A mudança da escola só se dará quando o trabalho for coletivo, articulado entre todos os atores da comunidade escolar, num exercício individual e grupal de trazer as concepções, compartilhá-las, ler as divergências e as convergências e, mediante esses confrontos, construir o trabalho. (ORSOLON 2003, p. 21)

Nesse sentido foi possível observar que há uma discrepância de conceitos no que tange o trabalho com crianças com deficiência, para alguns professores fica evidente a necessidade de ajuda que alguns alunos apresentam, outros confundem as limitações cognitivas com falta de interesse ou preguiça por parte da criança e até mesmo dos pais Stainback (1999), alerta que salas de aulas inclusivas são aquelas onde a diversidade fortalece toda a turma e essa diversidade é valorizada e oferece a todos os envolvidos maiores oportunidades de aprendizagem.

Dos 10 professores entrevistados, $40 \%$ não reconhecem o papel do coordenador como agente de formação no que tange a proposta de uma atuação voltada para educação inclusiva, acrescenta ainda que a formação deve ser ofertada pela Secretaria de Educação, pois além de capacitar os professores dessa escola, precisam disponibilizar formação para todos os professores da rede, visto que o aluno é da rede de ensino e não patrimônio de uma única escola. Ressalta que o coordenador também não tem formação para instrumentalizar os professores, uma vez que o mesmo tem formação em pedagogia como os demais colegas. Outros $30 \%$ diz não se interessar pelas atividades propostas pela coordenação e argumenta que estas aumentam sua demanda de trabalho. $20 \%$ respondeu que são orientadas, mas não aplica, pois recebe apenas orientações, porém precisam desenvolver as atividades e acreditam que o ideal seria ter uma pessoa destinada apenas para lidar com os alunos com deficiência, sem que a presença destes interferissem na aula dos demais. E 10\% reconhece que são auxiliados pela coordenação pedagógica e que tais orientações facilitam o 
trabalho com alunos com deficiência e pontuam que mediante um trabalho em parceria os avanços dos educandos têm sido significativos.

Aqui nos lembraremos da importância do atendimento educacional especializado (AEE) serviço que se ocupa da identificação, planejamento, aplicação e preparação de materiais pedagógicos adaptados que otimizem a participação dos alunos com deficiência incluídos no ensino regular objetivando especialmente o seu desenvolvimento bem como sua aprendizagem.

Os professores desempenham um papel fundamental no processo inclusivo, no entanto precisam estar preparados e confiantes nesse trabalho, é preciso ser ofertado instrumentos necessários para que possam olhar para todos os alunos, deficiente ou não, potencialmente capazes de aprender.

Todo aluno, independente das dificuldades advindas de sua deficiência, poderá, a seu modo e em seu tempo, beneficiar-se de programas educacionais, desde que lhe sejam dadas oportunidades adequadas para que possa desenvolver o seu potencial de aprendizagem e, consequentemente, integrar-se. (Mazzotta, 1987 )

Pode-se entender que a coordenação pedagógica se gesta como sendo uma assessoria permanente e continuada ao trabalho docente, cujas principais atribuições, dentre outras, podem ser listadas em quatro dimensões como aponta Piletti (1998, p. 125):

a) Acompanhar o professor em suas atividades de planejamento, docência e avaliação;

b) Fornecer subsídios que permitam aos professores atualizarem-se e aperfeiçoarem-se constantemente em relação ao exercício profissional;

c) Promover reuniões, discussões e debates com a população escolar e a comunidade no sentido de melhorar sempre mais o processo educativo;

d) Estimular os professores a desenvolverem com entusiasmo suas atividades, procurando auxiliá-los na prevenção e na solução dos problemas que aparecem.

Esse ponto que emergiu da entrevista, merece destaque uma vez que, os alunos são negligenciados em suas necessidades por que professores e coordenação pedagógica não são instrumentalizados para elaborar projetos educativos ou deixam de promover atividades pedagógicas capazes oportunizar a aprendizagem dos alunos independentemente de suas limitações, uma vez que não conseguem estabelecer um diálogo coeso e consistente acerca de como se constrói a aprendizagem humana nas mais diferentes apresentações.

\section{Questão - 02 - Com que frequência você participa de cursos de formação voltados para a inclusão de alunos com Deficiência Intelectual?}


As respostas a essa pergunta trouxeram um entendimento da dificuldade apresentada anteriormente pelos professores, no que tange ao encontro de professores e coordenação pedagógica no amparo metodológico que contemple a aprendizagem dos alunos com deficiência. Aqui um alto percentual de professores revelou ter não ter tido, até o momento da pesquisa, oportunidade de participar de cursos de capacitação na área de Educação inclusiva.

Do contingente de 10 professores, $90 \%$ dos entrevistados, respondeu nunca ter participado de curso de formação continuada na área de educação inclusiva. E acrescentaram que não consideram palestras pontuais, as quais já haviam assistido esporadicamente, suficientes para formar o professor para atuar com questões específicas.

Quanto a isso Nóvoa 1995, afirma que:

A formação não se constrói por acumulação (de cursos, de conhecimentos ou de técnicas), mas sim através de um trabalho de reflexividade crítica sobre as práticas e de (re)construção permanente de uma identidade pessoal. Por isso é tão importante investir a pessoa e dar um estatuto ao saber da experiência [...]. Práticas de formação que tomem como referência as dimensões colectivas contribuem para a emancipação profissional e para a consolidação de uma profissão que é autônoma na produção dos seus saberes e dos seus valores.

Mantoan, (2005), corrobora com esse pensamento, pois afirma que o professor precisa de uma boa formação para ensinar e que a sala de aula é um espaço de diversidade humana, o que impossibilita que se tenha um método pré-formulado para atender aos indivíduos. Para a mesma autora, a educação inclusiva é algo que se constrói no cotidiano da sala de aula por meio da reflexãoação-reflexão, ou seja, a efetivação da práxis pedagógica.

Aqui cabe lembrar que há uma diferenciação entre docentes com especialização e docentes para os atendimentos especializados e professores capacitados para atuarem nas classes comuns das escolas regulares. Como LDB descreve em seu documento "Diretrizes Nacionais para a Educação Especial na Educação Básica", de 2001 (BRASIL, 2001), traz a seguinte definição para os termos professores capacitados e professores especializados e descreve a atuação de cada um.

- Professores capacitados são aqueles que na sua formação acadêmica, tem disciplinas especificas voltadas para a educação especial, desse modo consegue perceber necessidades de flexibilização nas ações pedagógicas para atender os alunos que precisam de mais apoio. Nesse caso o professor é informado e não formado. Esse tipo de ação não garante a preparação do professor.

- Professores especializados, são aqueles que tem especialização voltada para atuar com crianças com deficiência. Transtornos globais do desenvolvimento e altas habilidades e devem apoiar aos professores que tiverem alunos com deficiência. 
Questão - 03 - Como você realiza o processo de avaliação da aprendizagem dos alunos com deficiência em relação aos demais alunos?

Mais uma vez o grupo abandona por alguns instantes o direito ao sigilo e compartilha suas inquietações. Queremos rememorar que o questionário foi respondido espontaneamente e individualmente no momento de conselho de classe ${ }^{1}$, o que contribui para discussões e reflexões, uma vez que nesse espaço e momento dialoga-se sobre aspectos referentes a escola como um todo, e os resultados alcançados durante a unidade são apresentados. O momento do conselho de classe é rico em discussões e a exposição de ideais é facilitada e as novas ações são planejadas. Sobre o Conselho de classe Dalben, 2004, p. 31 entende que:

Conceber o Conselho de Classe como um órgão colegiado em que vários professores das diversas disciplinas, juntamente com os coordenadores pedagógicos ou mesmo os supervisores e orientadores educacionais, reúnem-se para refletir e avaliar o desempenho pedagógico dos alunos das diversas turmas, séries ou ciclos. (DALBEN, 2004, p. 31)

Reafirmamos as observações, quando ao tabular os dados e como resultado do universo de 10 entrevistados, $30 \%$ avalia de forma processual, através das observações realizadas durante as aulas, mas não adaptam nenhuma atividade, costumam aproveitar o que o aluno consegue fazer, $30 \%$ aplicam atividades diferenciadas com o desejo apenas de manter os alunos com deficiência ocupados de alguma maneira, sem necessariamente ter um objetivo ou projeto pedagógico específico. $\mathrm{Na}$ maioria das vezes, tais atividades não estão em conformidade com o conteúdo que está sendo aplicado para os demais alunos, e não chegam a ser nem mesmo corrigidas, quanto a isso os professores justificam que esses alunos não vão para a escola para aprender, vão apenas para socializar. Dou uma atividade para que ele não fique sem fazer nada. (transcrição da fala da professora $\mathbf{C}$ ).

$30 \%$ dizem que adaptam apenas no período das provas, pois precisam apresentar a coordenação e aos pais algo que a criança tenha produzido durante o período de provas uma vez que precisam atribuir uma nota, visto que esse aluno também precisa ser avaliado. Mas isso é só para constar, para não pensar que não dou atenção para eles. (Transcrição da fala da professora D), apenas $10 \%$ dos entrevistados dizem fazer atividades adaptadas e processuais, as quais lhes dão base para fazer um parâmetro dos avanços conseguidos pelos alunos com deficiência em relação aos ditos "normais" durante as aulas ministradas. A professora F disse que costuma aplicar todos os conteúdos de maneira mais concreta possível, "desse modo consigo alcançar todos os níveis de aprendizagem de minha turma, independente do aluno ter ou não uma deficiência”.

\footnotetext{
${ }^{1}$ O conselho de classe é o período reservado dentro da carga horária afim de proporcionar diálogo professor, coordenador pedagógico e professor, acerca do cotidiano escolar, bem como apresentação do resultado da aprendizagem dos alunos. Também conhecido como AC - Atividade Complementar.
} 
Com base nos dados extraídos e na observação das discussões, é possível perceber que poucos professores se empenham em fazer um trabalho para incluir os alunos com deficiência. O que torna o trabalho pedagógico difícil repousa na questão da formação e outros da prática pedagógica calcificada numa metodologia tradicional, que entende a aprendizagem a partir das notas alcançada nas avaliações de final de bimestre.

O PPP, Projeto Político Pedagógico ²está expresso na LDBEN - Lei No. 9.394/96 que, em seu artigo 12, garante ao professor autonomia para construir uma democracia no seu cotidiano escolar através de pequenas ações da organização pedagógica. Aqui podemos pensar em oportunizar atividades em sala de aula que contemple a todos e oportunize a interação entre os alunos, sistematização do AEE, de preferência no contra-turno, preparar e executar as atividades de forma interativa onde todos aprendem e ensinam.

E é nisto que a escola deve centrar sua atenção: como se podem criar possibilidades de aprendizagem no contexto escolar, interpondo uma substancial mudança de foco, onde as dificuldades não são aprendidas simplesmente como fatores inerentes a condição biológica, mas como, também, provenientes das limitações do contexto social, no caso, escolar (OLIVEIRA, 2012, p.18).

A avaliação quando realizada da maneira correta, isto é, com o desejo de conhecer a maneira que o aluno aprende, bem como conhecer suas habilidades individuais, norteia a prática pedagógico e oportuniza ao professor uma retomada de ações partindo do conhecimento empírico dos alunos, assim como o ritmo e interesse de cada um.

\section{Questão -04 - O que você conhece sobre o Atendimento Educacional Especializado?}

Obtivemos os seguintes dados: 50\% compreende e apoia o trabalho do AEE, $30 \%$ compreende o AEE pois o descreve indicando de forma coerente a sua função e $20 \%$ confunde o AEE com reforço escolar, uma vez que responde que no AEE é feito um reforço para que o aluno possa aprender os assuntos dados em sala de aula, mas muitos deles não tem interesse em aprender e o reforço quase não funciona. (Resposta das professoras I e J).

O AEE é uma prática pedagógica essencial para a efetivação da educação inclusiva. É preciso que a escola compreenda qual é a função do AEE junto a sala de aula regular, a falta de entendimento acerca desses serviços tende a comprometer a plenitude dos resultados que se deseja alcançar e que são exarados no PDI- Plano de Desenvolvimento Individualizado, compreender o trabalho do AEE é desmistificar a essência da educação inclusiva. Quanto a isso Mantoan (2006) coloca:

A inclusão escolar tem sido mal compreendida, principalmente no seu apelo a mudanças nas escolas comuns e

\footnotetext{
${ }^{2}$ PPP- Projeto Político Pedagógico refere-se ao plano de atividades pedagógicas, elaborado pelos professores e gestores da escola com o desejo de atender de forma singular a comunidade escolar, levando em conta suas especificidades.
} 
especiais. Sabemos, contudo, que sem essas mudanças não garantiremos a condição de nossas escolas receberem, indistintamente, a todos os alunos, oferecendo-lhes condições de prosseguir em seus estudos, segundo a capacidade de cada um, sem discriminações nem espaços segregados de educação. (MANTOAN, p. 23).

O AEE para alunos com deficiência intelectual, implica em propor condições para que esse aluno passe de uma aprendizagem automática e mecânica para algo que vislumbre suas experiências cotidianas o que Piaget chama de regulações ativas ${ }^{3}$, o que possibilita uma tomada de decisão intelectual o que vai garantir uma autonomia para gerir as próprias ações.

\section{Questão - 05 - Você acredita que o AEE pode facilitar o trabalho pedagógico com alunos com deficiência? De que forma?}

Como refletem os dados acima, 50\% dos entrevistados diz que o AEE facilita muito a aprendizagem dos alunos com deficiência em sala de aula, para eles os alunos ganham autonomia $\boldsymbol{e}$ se dispõem a aprender cada um dentro da sua condição. (Professoras A, B, C, D, E) Outros 30\% dos entrevistados dizem que o AEE contribui de forma pouco significativa para aprendizagem dos conteúdos aplicados na sala de aula. Acho que devia ensinar mais a ler e escrever, pois as atividades ensinadas no AEE, não são as mesmas que dou na sala. (Síntese da fala das professoras, G, H, I). E $20 \%$ acha que não vê progresso e justifica que para elas aprendizagem é quando se apropria de leitura e escrita. (Professoras F, J).

Questão - 06 - De que maneira uma sala multifuncional com AEE pode contribuir efetivamente para a inclusão de alunos com deficiência intelectual de forma plena?

De um universo de 10 entrevistados, $40 \%$ não respondeu a questão, $40 \%$ disse não ter conhecimento do que é de fato uma sala multifuncional e para que serve e os $20 \%$ restantes revelou acreditar que a sala multifuncional pode tornar a inclusão mais efetiva, visto que é munida de recursos e profissionais com formação específica para tal situação.

Os dados apresentados nessa questão trazem em si a necessidade de discussão dos procedimentos que tornam possíveis a educação inclusiva e o que instrumentaliza essa modalidade de ensino. Quando percebemos que um grande percentual de educadores não (re)conhece o AEE, serviço essencial para a reabilitação dos alunos com deficiência e que trabalha em parceria com as salas de aula comuns, por tanto auxiliando o professor em sua prática pedagógica de inclusão.

A falta de diálogo, de conhecimento, entendimento e de articulação entre os professores de sala de aula comum e os professores de AEE está atrelada à incompreensão sobre as funções desse

\footnotetext{
3 Piaget (1978)... "fazer é compreender em ação uma determinada situação, em grau suficiente para atingir as mesmas situações, até poder resolver os problemas por ela levantados, em relação ao "porquê" e ao "como" das ligações constatadas e, por outro lado, utilizadas na ação" (p.176).
} 
serviço no processo de inclusão e como este pode assessorar mutuamente o trabalho com alunos público alvo da educação inclusiva.

\section{CONSIDERAÇÕES FINAIS}

Através das respostas dos professores, obtidas nos questionários e nas observações dos diálogos dos mesmos nos momentos de AC -Atividade complementar, ficou claro que o principal entrave entre a sala de aula comum e a sala de AEE. A educação especial na perspectiva da educação inclusiva perpassa todos os níveis e etapas da educação básica, o AEE que faz com que tal orientação se concretize. Nesse sentido, a falta de reestruturação curricular, ausência de práticas pedagógicas voltadas para a educação inclusiva, formação docente obsoleta, e sobretudo, à falta de diálogo entre os profissionais de salas de aula regular e àqueles que lecionam no AEE se constitui um entrave para a educação como um todo e em especial para a educação inclusiva, uma vez que esta tem procedimentos bem específicos, dadas as suas demandas.

Essa falta de consenso impossibilita a elaboração de um plano pedagógico que contemple a aprendizagem do aluno com deficiência se ancora em grande parte na insensibilidade dos agentes que compõem a processo escolarizador e denuncia que por vezes o professor quer sejam da sala de aula regular, quer seja da sala de AEE não concebam parceiros na efetivação da educação inclusiva.

Todos estes diálogos e tomadas de atitudes ao serem articuladas à educação inclusiva, significam muito mais do que discutir a respeito de deficiências ou da condição social do estudante deficiente. Significa que embora estes indivíduos tenham suas limitações assim como todos os seres humanos, eles são produtivos e articulados não apenas como seres depositados nas salas de aula, mas como sujeitos que colaboram com a construção de uma educação sociologicamente mais equânime.

\section{REFERÊNCIAS}

BRASIL, Lei $n^{o} 9394$ de 20 de dezembro de 1996. Estabelece as Diretrizes e Bases da Educação Nacional. Diário Oficibal da União. Brasília, nº 248, 23/12/1996.

BRASIL. Ministério da Educação - Secretaria de Educação Especial. Política nacional de educação especial na perspectiva da educação inclusiva. Brasília: MEC/SEESP, 2008. Disponível em: 〈http://portal.mec.gov.br/seesp/arquivos/pdf/politica.pdf>.

BRASIL. Ministério da Educação. Secretaria da Educação Especial. Política Nacional de Educação Especial, na perspectiva da Educação Inclusiva. Brasília:MEC/SEESP, 2008.

BRASIL. Ministério da Educação - Secretaria de Educação Especial. Secretaria de Educação a Distância. Formação continuada a distância de professores para o atendimento educacional especializado: deficiência física. Brasília: MEC/ SEESP/SEED, 2007. Disponível em: 〈http://portal.mec.gov.br/seesp/arquivos/pdf/aee_df.pdf $\rangle$. 
BRASIL. Ministério da Educação. Diretrizes nacionais para a educação especial na educação básica - Secretaria de Educação Especial. -. MEC; SEESP, 2001. 79 p. 1

DALBEN, AngelaI.L.F. Conselhos de classe e avaliação do projeto-político-pedagógico de escola. Revista Presença Pedagógica, Belo Horizonte, ano X, n. 60, p. 43-53, 2004.

GIL, A. C. Como elaborar projetos de pesquisa. 4. ed. São Paulo: Atlas, 2007.

LUDKE, M. ANDRÉ, M.E.D.A. Pesquisa em educação: abordagens qualitativas. São Paulo: EPU, 1986.

MALHOTRA, N. Pesquisa de marketing: uma orientação aplicada. 4.ed. Porto Alegre: Bookman, 2006.

MANTOAN, Maria Teresa Eglér. Igualdade e diferenças na escola: como andar no fio da navalha. In: ; PRIETO, Rosângela Gavioli. Inclusão escolar: pontos e contrapontos. São Paulo: Summus, 2006, p. 15-29.

MANTOAN, Maria Teresa Eglér. Inclusão é o Privilégio de Conviver com as Diferenças. In Nova Escola, maio, 2005.

MAZOTTA, M. J. da S. Educação Escolar: comum ou especial. São Paulo: Pioneira,1987.

NÓVOA, A. Formação de professores e profissão docente. In: NÓVOA, A. (Coord.). Os professores e a sua formação. Lisboa: Dom Quixote, 1995.

OLIVEIRA, A. A. S. Deficiência Intelectual: os sentidos da cultura, da história e da escola.In: SAO PAULO (cidade). Secretaria Municipal de Educação. Diretoria de Orientação Técnica. Referencial sobre Avaliação da Aprendizagem na área da Deficiência Intelectual -Ciclo II do Ensino Fundamental e da Educação de Jovens e Adultos. Secretaria Municipal de Educação - São Paulo: SME/DOT, 2012.

ORSOLON, Luzia Angelina Marino. O coordenador/formador como um dos agentes de transformação da/na escola. In: ALMEIDA, Laurinda Ramalho de; PLACCO, Vera Maria Nigro de Souza (Orgs). O Coordenador Pedagógico e o Espaço de Mudança. São Paulo: Loyola, 2003.

PILETTI, N. Estrutura e funcionamento do ensino fundamental. São Paulo: Ática, 1998.

STAINBACK, Susan e Willian. Inclusão: um guia para educadores. Porto Alegre: editora Artmed, 1999.

TRIVIÑOS, A. N. S. Introdução à pesquisa em ciências sociais: a pesquisa qualitativa em educação. São Paulo: Atlas, 1987 